\title{
The role of social networks in personality analysis for recruitment of laureates: A systematic review and exploratory study
}

\author{
Qostal Aniss ${ }^{(1, *)}$, Moumen Aniss ${ }^{(2)}$, Lakhrissi Younes ${ }^{(1)}$ \\ (1) S.I.G.E.R laboratory, Faculty of Science and Technology Fez, Morocco Affiliation \\ (2) Laboratory of Engineering Sciences, ENSA Kenitra, Ibn Tofail University, Morocco \\ Email*: aniss.qostal@usmba.ac.ma
}

\begin{abstract}
Today, the recruitment process has seen a drastic change in the measure of the personality aspect of the candidates. Accordingly, in the era of digitalization and the proliferation of the professional social network, the selection of valuable information provided from the candidate's accounts has a primordial role in the selection of the profiles responding to job offers and to create a global vision on the personality and the capability of the job seekers from teamwork and leadership to meet the job requirements. The paper aims to discover the approaches applied in the personality analysis based on the professional networks. Beginning with a systematic review of previous works and exploratory analysis through interviews with stakeholders participated in the recruitment process.
\end{abstract}

Keywords: Professional social network, personality analysis, recruitment process, systematic review, exploratory analysis.

\section{Introduction}

Nowadays, the recruitment process has known a great development and shown a continuous change in terms of techniques applied in the process of pre-selection, selection, and integration of candidates in the workplace. Nevertheless, the procedure of recruitment is considered one of the main challenges for human resource management; especially the performance of the companies is related in the first place to the quality of new talents integrated into the teamwork.

Accordingly, many studies have proven the real link between the performances of companies, their competitiveness in the workplace, even innovations with the quality of the process of integrating new talents [1].

Therefore, the HR departments have to improve their methods of managing the human capital in the entire cycle of recruitment; and taking the personality of each new employee into consideration, and develop new approaches to identify the mains traits of personalities that can be the base of decisions and even predicting of the performance and the effectiveness within teamwork[2].

In fact, personality analytics has gained importance within the selection of talents in parallel with skills (soft and hard) needed in the marketplace. The majority of job providers tend to develop new methods to evaluate the attitude of each candidate as an indicator of adaptation to the workplace environment. Therefore, the big five model has become very

Corresponding author: aniss.qostal@usmba.ac.ma 
popular as a standard for the investigation on the relation of the "Big Five" personality dimensions (Extraversion, Emotional Stability, Agreeableness, Conscientiousness, and Openness to Experience) within many contexts of research related to the recruitment process.

In this paper, our objective is to study the application of the big five model with new techniques based on data generated on the web over platforms, including Social networking services (SNS), with the aim to discover the reliability of data from these platforms and big five model to enhance the integration of youth people and give answers to questions such as:

- Could the data generated over SNS be base on the big five model on the recruitment process?

- What is the dimension of the personality traits that can be extracted from SNS and can be relevant?

The results obtained from the systematic review will be compared with the exploratory study obtained from interviews made in this context with professional stakeholders on the recruitment process in the Moroccan context.

\section{Related works}

Nowadays, the application of data analytics on personality traits within the recruitment process has become very important and popular [3], [4]. Therefore, the prediction of job performance in different fields of competence through the big five model has shown good results and definition of each dimension in different contexts and situations in the professional world. Where the model of Big Five traits of personality aims to group the essential characteristics into five groups:

- Extraversion: represents the degree of social interactions within a group, people with high scores is more social and looking for establishing human relationships.

- Emotional Stability (Neuroticism): emotional sensitivity including the degree of depression, anxiety, and vulnerability towards different situations.

- Agreeableness: relate to the degree of tolerance and flexibility towards others and other opinions.

- Conscientiousness: about the discipline, organization, and responsibility towards agreement.

- Openness to Experience: represents the aptitude of discovering new experience new projects and new plans, the person with high score tend to be more curious, and creative.

Furthermore, the application of machine learning techniques over the data generated on the web becomes the base for the application of different approaches and research on the personality characteristics to predict the behaviours of applicants towards the job's requirements. Accordingly, to discover the reliability of data in the SNS and using the data gathered from LinkedIn, which is considered as the most used platform by $92 \%$ of recruiters, the collection of information on the potential applicant showed that the profile information might contain indicators on Agreeableness and openness to experience [5]. Additionally, the extraversion traits can be predicted using data from LinkedIn [6]. Otherwise, the Facebook platform, which is considered as an entertainment platform, the collection of the information related to the personality traits and recruitment context and compared to website standalone the Conscientiousness, Extraversion were both significantly lower. At the same time, Agreeableness and Openness to Experience were higher in this platform [7]. 


\section{Research methodologies}

The methodology adopted in the research is primarily to answer to questions about the data generated in the virtual world and how it can be a base for the development of the recruitment process, especially for the aspect of personality analytics. Accordingly, for our approach, we have adopted two main lines (figure 1); firstly, building a systematic review on the scientific works through the collection of scientific researches, articles, and studies from the main indexed scientific journals and digital databases represented on: IEEE Xplore, Scopus, and Web Of Science targeting the studies with three major criteria related to the recruitment process, the personality analysis and the data generated over SNS. The result obtained is represented in the RIS format was imported on the ZOTERO platform to do the cleaning phase by deleting documents not related to our research, filling the missing fields for the meta-analysis; merge double documents, and accept the document published in the time range over the current decade [2010-2020]. The analytics part is made through the probabilistic approach represented with the Latent Dirichlet Allocation (LDA) with the aim of the transformation of each document on a number of small topics [8] and calculate the coherence within the corpus. The second line is based on the interviews with different job providers in different fields of competence.

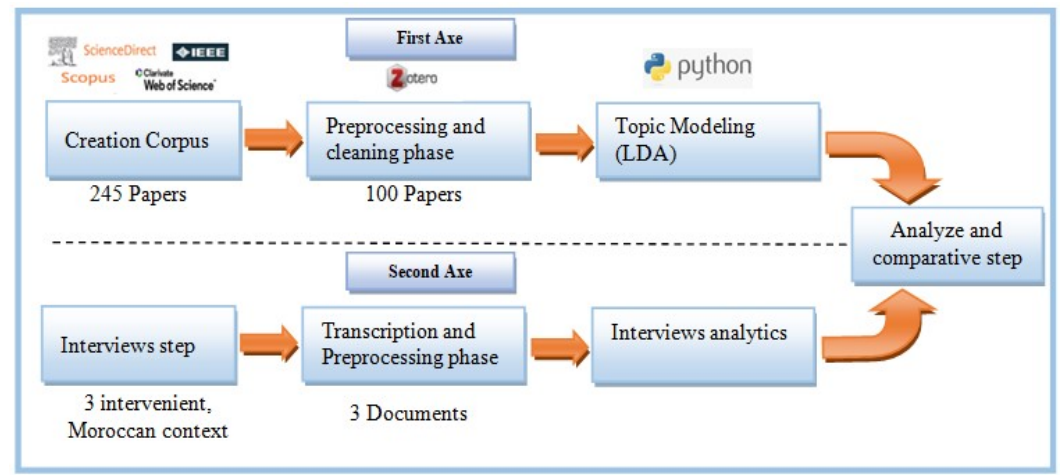

Fig. 1: the systematic and exploratory methodology adopted.

\section{Results and discussion}

\subsection{First line: Systematic review}

\subsubsection{Corpus distribution analysis}

The corpus distribution analysis tends to discover the publication of papers for each journal in a defined timeline. For our case, the collection process was made for publications within the interval between 2010 and 2021. Accordingly, from the result obtained as presented in figure 2; the publications focusing on the use the novel technologies and approaches targeting the use of data from social media, big data, machine learning, and personality analytics on the recruitment process has gained importance over different journals in last few years. 


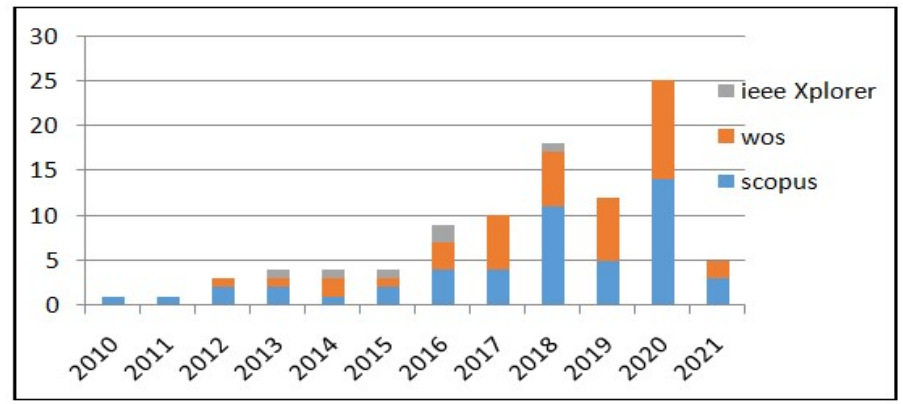

Fig. 2: the distribution of publications between 2010 and 2021.

\subsubsection{Frequency Analysis of Keywords}

The results obtained from the first line can be presented in many ways; the most used method is the word cloud technique. Therefore, the objective is to highlight the dominants words and terms in the corpus (Figure 3), as represented for our research the most dominants words are; social media, big five, personality traits, machine learning, recruitment process, and big data. These terms show and prove a line of research is gaining attention on the development of models for the recruitment process using data from social media and machine learning to predict and validate models of personality traits like the big five model.

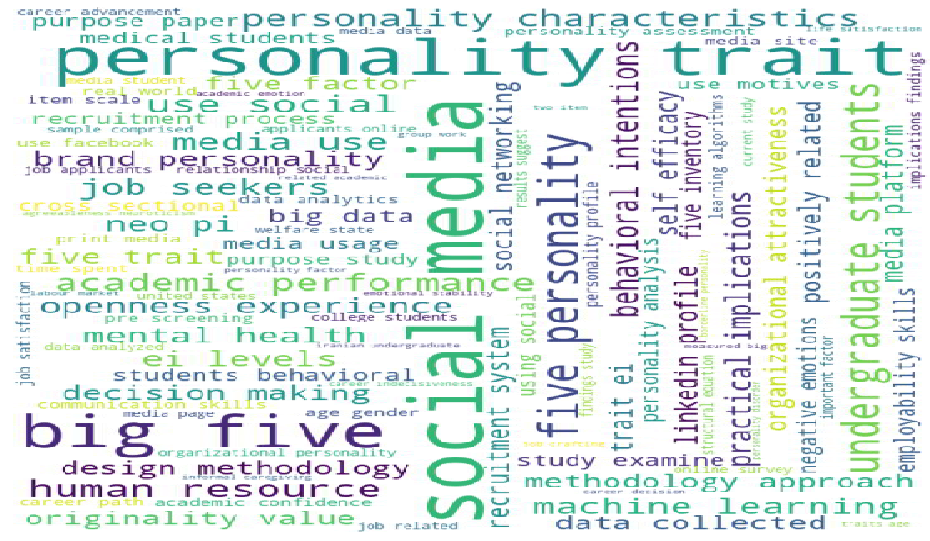

Fig. 3: word cloud of terms from the corpus.

\subsubsection{LDA analysis}

The topic modelling can be done in many ways; accordingly, we use the LDA to highlight the dominant topics within the corpus and their dominants terms. The number of topics can be made manually or through the coherence coefficient and perplexity scores (Figures 4). Mainly, we choose six topics as results obtained from GENSIM implementation on the preprocessed corpus. 
Fig 4: coherence score against the number of topics.

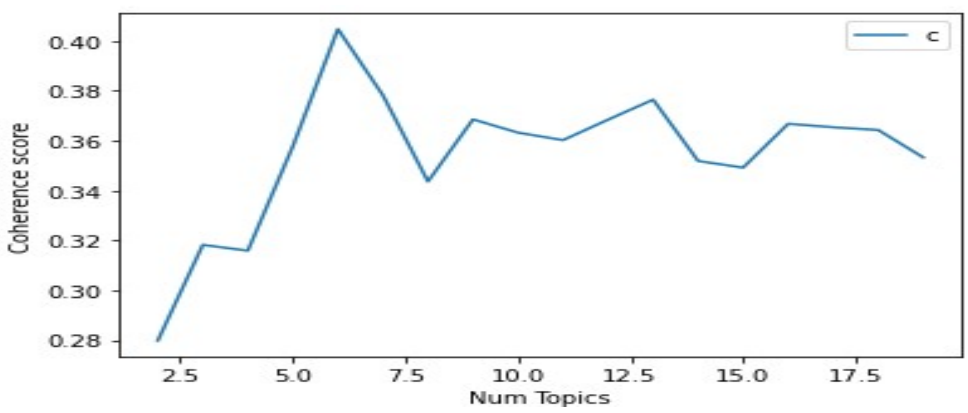

The visualization provided with the LDAvis library (figure 5) shows the separation of the six topics, which indicates the reliability of the coherence coefficient and perplexity scores. Therefore, we can conclude dominant terms for the overall topics (figue7) and separately for each one (Table 1).

Fig 5: the projection of topics based on LDAvis

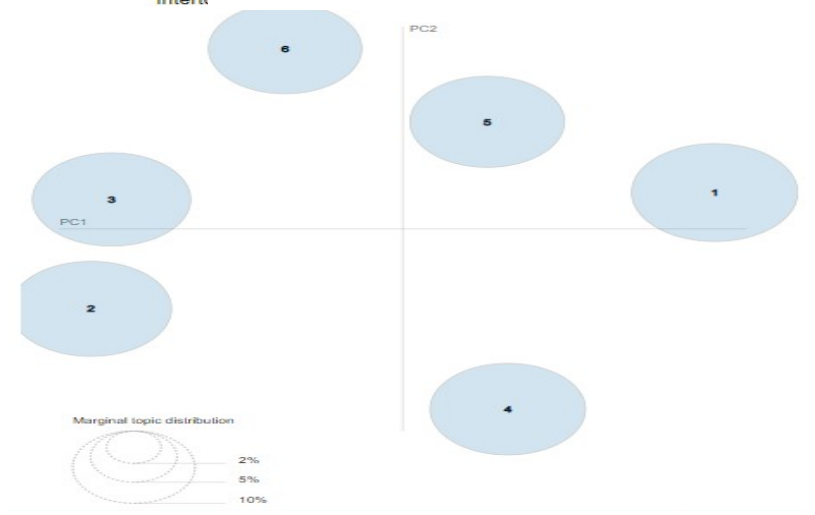

Table 1. Papers discuss the implementation of the big five model based on data from SNS

\begin{tabular}{|c|c|c|}
\hline Paper & Description \& methodology & results \\
\hline [7] & $\begin{array}{l}\text { Collect data from facebook } \\
\text { platform, to extract essential trait of } \\
\text { personality and test the big five } \\
\text { model for the undergraduate } \\
\text { compared to data collected over } \\
\text { personality inventory(100 question } \\
\text { IPIP-NEO) }\end{array}$ & $\begin{array}{l}\text { As results, features extracted from facebook compared } \\
\text { to the personality inventory are Extraversion and } \\
\text { Openness to Experience with the score } 0.93 \text { and } 0.85 \\
\text { respectively. Otherwise Conscientiousness is not related } \\
\text { to data from facebook. }\end{array}$ \\
\hline [8] & $\begin{array}{l}\text { Use data from the facebook profiles } \\
\text { to predict the personality traits in } \\
\text { many context including job } \\
\text { satisfaction and administration of } \\
\text { Big Five Personality Inventory to } \\
279 \text { subjects containing } 45 \\
\text { questions. }\end{array}$ & $\begin{array}{l}\text { Using two machine learning algorithms }-\mathrm{m} 5 \mathrm{sup} / \text { Rules } \\
\text { and Gaussian Processes -, the identification of each of } \\
\text { the the five personality traits. As results M5'Rules and } \\
\text { Gaussian Processes produce results with strong } \\
\text { correlations }(\rho>=0.5) \text { on Openness, Conscientiousness, } \\
\text { Extroversion and Neuroticism, and a medium } \\
\text { correlation }(0.3<=\rho<0.5) \text { on Agreeableness }\end{array}$ \\
\hline [9] & $\begin{array}{l}\text { Use data collected from twitter to } \\
\text { establish an emotional system form } \\
\text { the recruitment process, using } \\
\text { ML(NB, SVM, LR) to predict big } \\
\text { five traits for Junior Programmer } \\
\text { and Senior Manager profiles. }\end{array}$ & $\begin{array}{l}\text { As result the model based on labeled dataset by } \\
\text { professional recruiter; the Random forest has the best } \\
\text { result with } 93 \% \text { precision and but the accuracy was for } \\
\text { Naïve bays. }\end{array}$ \\
\hline
\end{tabular}


The topics obtained from the treatment of the corpus contain multiple types of research on the application of data obtained from the SNS with objective determine the personality traits (Table1), additionally The top 30 terms of the topics modelling obtained with LDA (Figure 6 and Table 2), the dominants world and terms are oriented personality analytics and use of data obtained from social media.

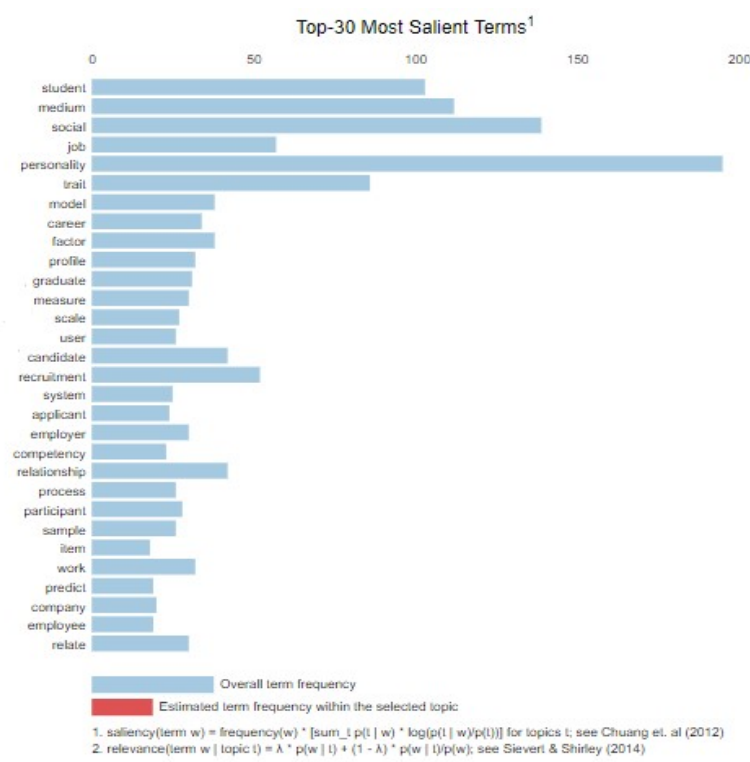

Fig.6: top 30 terms of the corpus with the topic modelling LDA.

Table 2. The dominant terms for each topic.

\begin{tabular}{|l|l|}
\hline Topic & Top ten relevant terms \\
\hline Laureates: $18.4 \%$ tokens & $\begin{array}{l}\text { Student, study, graduate, employer, competency, skill, } \\
\text { undergraduate, communication, practice, research }\end{array}$ \\
\hline $\begin{array}{l}\text { Social media: } 17.3 \% \\
\text { tokens }\end{array}$ & $\begin{array}{l}\text { Personality, traits, job, social, media, profile, recruitment, } \\
\text { system, applicant, approach. }\end{array}$ \\
\hline $\begin{array}{l}\text { Prediction \& personality: } \\
16.7 \% \text { tokens }\end{array}$ & $\begin{array}{l}\text { Personality, social, media, model, education, behaviour, } \\
\text { analyze, employee, predict, performance. }\end{array}$ \\
\hline $\begin{array}{l}\text { Traits \& performance: } \\
16.1 \% \text { tokens }\end{array}$ & $\begin{array}{l}\text { Trail, study, career, emotion, college, academic, } \\
\text { socialization, positively, quality, performance. }\end{array}$ \\
\hline $\begin{array}{l}\text { Personality measurement: } \\
15.9 \% \text { tokens }\end{array}$ & $\begin{array}{l}\text { Personality, factor, measure, scale, extraversion, openness, } \\
\text { correlation, student, undergraduate, Facebook. }\end{array}$ \\
\hline $\begin{array}{l}\text { Recruitment : } 15.6 \% \\
\text { tokens }\end{array}$ & $\begin{array}{l}\text { Social, candidate, participant, analysis, hire, recruitment, } \\
\text { personality, attitude, interview, employment. }\end{array}$ \\
\hline
\end{tabular}

\subsection{Exploratory study}

\subsubsection{Context}

The second line has the aim to extract information and features from the real and professional world about the process of recruitment, strategies applied and perspective to develop and facilitate the integration of jobseekers on the marketplace. Accordingly, we adopted the exploratory strategies throw the interviews method; we made different 
meetings with different actors in different fields of competence about the recruitment process in the Moroccan context, as showed in Table 3.

Table 3. List of participants in the interviews

\begin{tabular}{|l|l|l|}
\hline Organization & Actor interviewed & \multicolumn{1}{|c|}{ Quality } \\
\hline Company A & $\begin{array}{r}\text { Manager of recruiting } \\
\text { agency }\end{array}$ & $\begin{array}{l}\text { Director of a cabinet of recruitment, advisor, } \\
\text { and trainer for several companies in the } \\
\text { recruitment area. }\end{array}$ \\
\hline Company B & Director and Manager & $\begin{array}{l}\text { Engineer, head of technical office and company } \\
\text { in the field of civil engineering }\end{array}$ \\
\hline Company C & Director and Manager & Director and responsible for IT company. \\
\hline
\end{tabular}

\subsubsection{Results and finding}

The interviews with actors in the real and professional world about the recruitment process and skills needed and finally the personality traits of the potential candidate and the principal source of information have shown different aspects of using different sources of information and different personality needed depending on the fields of competence (Table 4).

Table 4. Different approaches and indicators for personality analysis based on interviews

\begin{tabular}{|c|c|c|c|}
\hline Volet & Company A & Company B & Company C \\
\hline $\begin{array}{l}\text { Domain } \\
\text { expertise }\end{array}$ & $\begin{array}{l}\text { Cabinet of recruitment } \\
\text { works with job } \\
\text { providers to find the } \\
\text { right talents for their } \\
\text { business }\end{array}$ & $\begin{array}{l}\text { Buildings and Public } \\
\text { Works and Civil } \\
\text { Engineering }\end{array}$ & $\begin{array}{l}\text { Specialized in the IT field, } \\
\text { development of projects and } \\
\text { applications for multinational } \\
\text { clients }\end{array}$ \\
\hline $\begin{array}{l}\text { Recruitment } \\
\text { process }\end{array}$ & $\begin{array}{l}\text { Recruit for itself and } \\
\text { for its clients }\end{array}$ & $\begin{array}{l}\text { Recruit directly or with } \\
\text { the help of the agency of } \\
\text { recruitment. }\end{array}$ & $\begin{array}{l}\text { Recruit directly or with the } \\
\text { help of the agency of } \\
\text { recruitment. }\end{array}$ \\
\hline Source of data & $\begin{array}{l}\text { CVs and interviews as } \\
\text { the principal source, } \\
\text { Linkedin as a } \\
\text { professional source, } \\
\text { Facebook as a } \\
\text { secondary source. }\end{array}$ & $\begin{array}{l}\text { Essential from CVs and } \\
\text { direct contact with the } \\
\text { applicant. }\end{array}$ & $\begin{array}{l}\text { CVs and direct contact, } \\
\text { technical attestations, } \\
\text { Linkedin, IT platforms like } \\
\text { GitHub, Sourceforge. The use } \\
\text { of social media is not very } \\
\text { used for the personality } \\
\text { analysis }\end{array}$ \\
\hline Personality traits & $\begin{array}{l}\text { The personality traits } \\
\text { required to depend on } \\
\text { the recruiter's area of } \\
\text { expertise. }\end{array}$ & $\begin{array}{l}\text { Interested in technical } \\
\text { competence at first } \\
\text { place, creative in finding } \\
\text { solutions and } \\
\text { discipline(Conscientious } \\
\text { ness and openness to } \\
\text { new experience) }\end{array}$ & $\begin{array}{l}\text { The IT field needs continuous } \\
\text { development, the share of } \\
\text { knowledge within teamwork, } \\
\text { and commitment in work } \\
\text { (Conscientiousness, and } \\
\text { openness to new experience, } \\
\text { extraversion) }\end{array}$ \\
\hline
\end{tabular}




\section{Conclusion}

The results obtained from the systematic review and the exploratory study on the role of personality analytics in the recruitment process and the prediction of the behaviours of the new talent show good results with the treatment of data from various sources, including SNS, especially with specifics dimensions including openness to new experience, extraversion, and agreeableness, which indicated the data collected over the web could contain relevant information. Nevertheless, the development of new techniques with taking advantage of ML as a way to job providers on the personality aspect in the Moroccan context is still in its infancy step where the use of new approaches is still not very developed.

\section{References}

[1] R. Hogan, J. Hogan, et B. W. Roberts, « Personality Measurement and Employment Decisions », American Psychologist, p. 9, 1996.

[2] M. R. Barrick et M. K. Mount, «THE BIG FIVE PERSONALITY DIMENSIONS AND JOB PERFORMANCE: A META-ANALYSIS », Personnel Psychology, vol. 44, n ${ }^{\circ}$ 1, p. 1-26, mars 1991, doi: 10.1111/j.1744-6570.1991.tb00688.x.

[3] W. Matcha et al., Analytics of learning strategies: the association with the personality traits. 2020, p. 160. doi: 10.1145/3375462.3375534.

[4] S. Hadji et H. Maymoun, «Emotion management in mathematics test », vol. 2019, $\mathrm{n}^{\mathrm{o}}$ 2, p. 8, 2019.

[5] N. van de Ven, A. Bogaert, A. Serlie, M. J. Brandt, et J. J. A. Denissen, « Personality perception based on LinkedIn profiles ", Journal of Managerial Psychology, vol. 32, $\mathrm{n}^{\mathrm{o}}$ 6, p. 418-429, 2017, doi: 10.1108/JMP-07-2016-0220.

[6] S. Q. Ma et L. Leung, « The Impacts of Personality Traits, Use Intensity and Features Use of LinkedIn on Bridging Social Capital », Applied Research Quality Life, vol. 14, no 4, p. 1059-1078, sept. 2019, doi: 10.1007/s11482-018-9635-y.

[7] S. C. Rife, K. L. Cate, M. Kosinski, et D. Stillwell, « Participant recruitment and data collection through Facebook: the role of personality factors », International Journal of Social Research Methodology, vol. 19, $\mathrm{n}^{\circ}$ 1, p. 69-83, janv. 2016, doi: 10.1080/13645579.2014.957069.

[8] D. M. Blei, « Latent Dirichlet Allocation», p. 30.

[9] J. Golbeck, C. Robles, et K. Turner, «Predicting personality with social media », in Proceedings of the 2011 annual conference extended abstracts on Human factors in computing systems - CHI EA '11, Vancouver, BC, Canada, 2011, p. 253. doi: 10.1145/1979742.1979614.

[10] V. M. Menon et H. A. Rahulnath, «A novel approach to evaluate and rank candidates in a recruitment process by estimating emotional intelligence through social media data », présenté à 2016 International Conference on Next Generation Intelligent Systems, ICNGIS 2016, 2017. doi: 10.1109/ICNGIS.2016.7854061. 